\title{
Correction to: A Systematic Review of the Facilitators and Barriers to the Sustained Implementation of School-Wide Positive Behavioral Interventions and Supports
}

\author{
Russell A. Fox (D) Erin S. Leif (D) \\ Dennis W. Moore $\mathbb{D}$ - Brett Furlonger • \\ Angelika Anderson • Umesh Sharma (D)
}

Published online: 27 October 2021

(C) Association for Behavior Analysis International 2021

\section{Correction to: Educ Treat Child https://doi.org/10.1007/s43494-021-00056-0}

There is an incorrect description of the IRR procedure for the literature inclusion / exclusion process within the article. On page 6 under the subheading "Interrater Reliability (IRR) Literature Inclusion", it currently reads "Percent agreement was calculated by dividing the total disagreements by the total agreements and multiplying by 100." Where it should read, "Percent agreement was calculated by dividing the total agreements by the total agreements plus disagreements and multiplying by $100 . "$

Publisher's Note Springer Nature remains neutral with regard to jurisdictional claims in published maps and institutional affiliations.

The original article can be found online at https://doi.org/ 10.1007/s43494-021-00056-0.

R. A. Fox $(\bowtie) \cdot$ E. S. Leif · D. W. Moore · B. Furlonger

U. Sharma

Faculty of Education, Monash University, 19 Ancora

Imparo Way, Clayton, VIC 3800, Australia

e-mail: russell.fox@monash.edu

A. Anderson

School of Psychology, Faculty of Arts and Social Sciences,

University of Waikato, Hamilton, New Zealand 